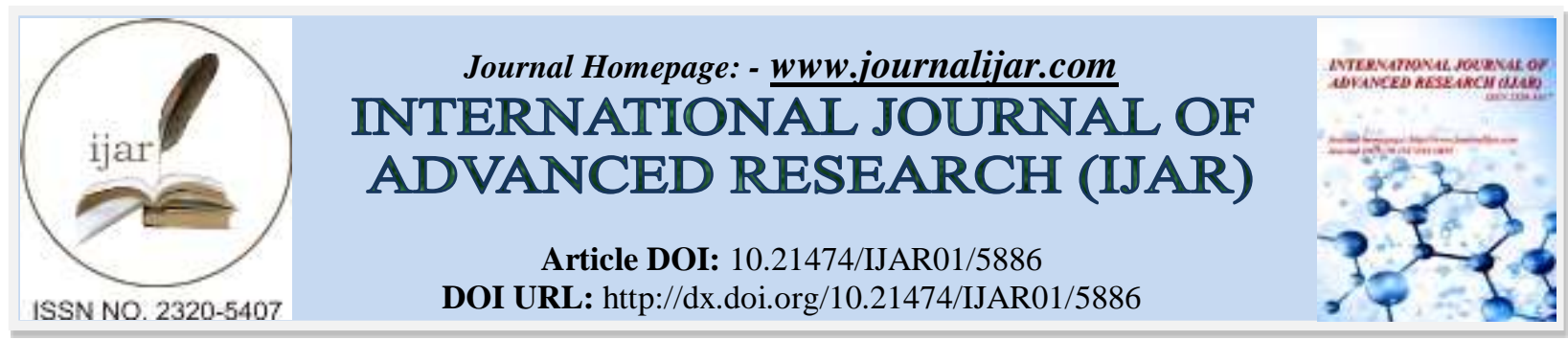

RESEARCH ARTICLE

\title{
AWARENESS AND DISASTER PREPAREDNESS OF BARANGAY DISASTER RISK REDUCTION AND MANAGEMENT COMMITTEES (BDRRMC'S) OF LAUR, NUEVA ECIJA, PHILIPPINES.
}

\author{
Aileen A. Villanueva and Paquito M. Villanueva. Jr.
}

\section{Manuscript Info}

\section{Manuscript History}

Received: 16 September 2017

Final Accepted: 18 October 2017

Published: November 2017

\section{Key words:-}

Organizational Effectiveness, Disaster Risk Reduction and Management, Flood and Landslide Prone Barangays, Organizational Evaluation, Barangay Officials.

\begin{abstract}
Natural disasters like typhoons and earthquakes are now frequently occurring in the country. The Philippine government had increased its efforts to implement the disaster risk reduction management (DRRM) program as its answer to the frequent occurrence. This paper gives an overview of the Awareness and Disaster Preparedness of the Barangay Disaster Risk Reduction and Management Committees (BDRRMCs) of Laur, Nueva Ecija, Philippines. It focused on the flood and landslideprone barangays of Laur, Nueva Ecija. The study used the Goal Model of Organizational Theory to measure the awareness of BDRRMCs. The awareness of BDRRMCs was measured against the goals and objectives of Republic Act 10121 also known as Philippines Disaster Risk Reduction and Management (DRRM) Act. The study used as a research tool the Checklist of Disaster Preparedness divided into four thematic areas namely; a) Disaster Prevention and Mitigation, b) Disaster Preparedness, c) Disaster Response, and d) Disaster Rehabilitation and Recovery. The study showed the need for periodic evaluation of the effectiveness of Barangay Disaster Risk Reduction and Management Committees (DRRMCs) and to set the standard of performance not only for the purpose of policy evaluation but also for measuring community involvement in disaster risk reduction. Results showed that BDRRMCs will be most effective if they are performing their functions and as prescribed by law, they should give priorities to all thematic areas, especially prevention and mitigation, and disaster preparedness to achieve the goals and objectives of RA 10121.
\end{abstract}

Copy Right, IJAR, 2017,. All rights reserved.

\section{Introduction:-}

The Philippines, a Southeast Asian nation is the most exposed country in the world to tropical storms of which frequently make landfall on the islands of Eastern Visayas and Northern Luzon. The country is prone to typhoon because it is geographically located along the Pacific region near the equator. Tropical storms are formed in areas near the equator because of the warm water of the biggest ocean, the Pacific Ocean, which is the country's neighbor. Typhoons trigger landslides and flash floods because it brings with its strong winds and torrential rains and sometimes storm surges [1]. The Philippines is exposed to disasters and hazards because of its geography and geology [2]. Our disaster management system traces back its origin to 1941 when President Manuel L. Quezon created Executive Order (EO) No. 335 establishing the National Emergency Commission and implementing measures to control and coordinate civilian participation to meet serious crises. Consequently, the Provincial Emergency Committee was created, in charge of the supervision and control over the Municipal Emergency

Corresponding Author:- Aileen A. Villanueva. 
Committees and City Emergency Committees. In 1954, the National Civil Defense Administration (NCDA) was established through Republic Act (RA) 1190, which also created national and local civil defense councils. In 2009, the Congress enacted the Climate Change Act of 2009 and in 2010, RA 10121 or the Philippine Disaster Risk Reduction and Management (PDRRM) Act. These twin laws on DRRM have common goals and objectives to increase the resilience of vulnerable communities and the country against natural disasters and to reduce damage and loss of lives and properties due to disasters. In particular, RA 10121 provides for the development of policies and plans and the implementation of actions and measures pertaining to all aspects of DRRM, including good governance, risk assessment and early warning, knowledge building and awareness raising, reducing underlying risk factors, and preparedness for effective response and early recovery. The law acknowledges that there is a need to "adopt a disaster risk reduction and management approach that is holistic, comprehensive, integrated, and proactive in lessening the socioeconomic and environmental impacts of disasters including climate change, and promote the involvement and participation of all sectors and all stakeholders concerned, at all levels, especially the local community [3].

Through Republic Act 10121, the National DRRM Framework (NDRRMF) and National DRRM Plan (NDRRMP) were developed. Both the NDRRMF and NDRRMP foresee a country which has "safer, adaptive and disasterresilient Filipino communities toward sustainable development". Together with the paradigm shift is the creation of the four thematic areas namely; a) Disaster Prevention and Mitigation, b) Disaster Preparedness, c) Disaster Response, and d) Disaster Rehabilitation and Recovery. Each area has long term goals and activities which will lead to the attainment of overall vision in DRRM. According to the NDRRMF, resources invested in the four thematic areas must prioritize disaster prevention and mitigation, disaster preparedness and climate change adaptation to be more effective in attaining its goal and objectives [4]. All of these were cascaded from national government to the barangay, the smallest political unit in the archipelago; and the nearest to the people in the localities serving as the primary planning and implementing unit of government programs, projects and activities [5]. As a political unit in grassroot level, the Barangay Disaster Risk Reduction and Management Committee (BDRRMC) mandate is to implement RA 10121 (Sec. 12 (a)).

Like many areas in the Philippines, Laur is frequently visited by typhoons. The two strongest typhoons that hit the municipality are Typhoon Pepeng and Pedring in 2009 and September 2011 respectively. Flooding and landslide is the primary hazard in Laur, Nueva Ecija. The Geo hazards Mapping and Assessment Team (GMAT) of the Mines and Geosciences Bureau Regional Office No. III (MGBR3) had conducted landslide/flood hazard assessment in the municipality of Laur and concluded that seven (7) barangays were very high for landslide susceptibility and also high in flood susceptibility [6]. Despite the importance of reducing risk during manmade or natural made calamities, there is an observable gap in knowledge on how to measure the effectiveness of government unit in-charged of lessening the impact of disasters. At present, there is no standard tool to measure their effectiveness in the performance of functions.

The Seal of Good Governance and the "Gawad Kalasag" are programs to measure performance of the LGU. The SGLG was implemented by the Department of Interior and Local Government (DILG). It is an improvement of the Seal of Good Housekeeping that was launched on 2010, and integrated with the Seal of Disaster Preparedness that was released on 2012. The SGLG recognizes good performance of the LGUs, not only on financial housekeeping, but also on areas that directly benefit the people, including disaster preparedness [7]. While Gawad KALASAG (Kalamidad at Sakuna Labanan, Sariling Galing ang Kaligtasan) was implemented by the National Disaster Risk Reduction and Management Council (NDRRMC) through the Office of Civil Defense (OCD). It is a Search for Excellence in DRRM and Humanitarian Assistance, which recognizes exceptional contributions of DRRM practitioners in strengthening the resilience and adaptive capacities of nations and communities on disaster risks [8]. However, these national programs have their own limitations. They cannot measure the effectiveness of the Disaster Risk Reduction Management System at the Barangay level. Thus, the study is designed to fill the Gap in terms of performance evaluation at the barangay level. This would in turn assess the awareness of the policies enacted by the national and the effectiveness of its implementation in the grassroots level. Performance measurement and program evaluation have been used and is essential for a more efficient, effective and accountable public sector [9]. Thus, an assessment at the barangay level is vital in the performance management of the local governments. 


\subsection{Objectives of the Paper}

The main objective of the study is to measure the organizational awareness and disaster preparedness of the BDRRMCs of the flood and landslide prone barangays in the municipality of Laur, Nueva Ecija based on Disaster Prevention and Mitigation, Disaster Preparedness, Disaster Response, and Disaster Rehabilitation and Recovery.

The study is aimed at measuring the organizational awareness and disaster preparedness of the flood prone barangays along the areas of:

1) Disaster Prevention and Mitigation using as parameters:

a) Risk Assessment

b) Plans, Policies, and Budget

c) Early Warning System

d) Risk Financing

e) Environmental Management

f) Infrastructure Resilience

2) Disaster Preparedness in terms of:

a) Presence of a functional Barangay Development Council (BDC)

b) Presence of an institutionalized Barangay DRRM Committee

c) Approved Plans

d) Capacity development activities conducted:

e) Partnership Mechanisms

3) Disaster Response;

4) Disaster Rehabilitation and Recovery;

5) The overall organizational effectiveness of the flood-prone barangays measured based on the four thematic areas of disaster risk reduction management.

6) To propose policy recommendation.

\section{Research Methodology}

\section{Study Locale}

The study locale is in Laur, Nueva Ecija located in the eastern part of the province of Nueva Ecija situated at the foot of the panoramic Sierra Madre mountains. It lies in a fertile valley along the santor river curved like a rainbow extending from the east and to the west. Most of the barangays of Laur are located within the topographical low areas of the municipality defined by different geomorphologic features. (Figure 1).

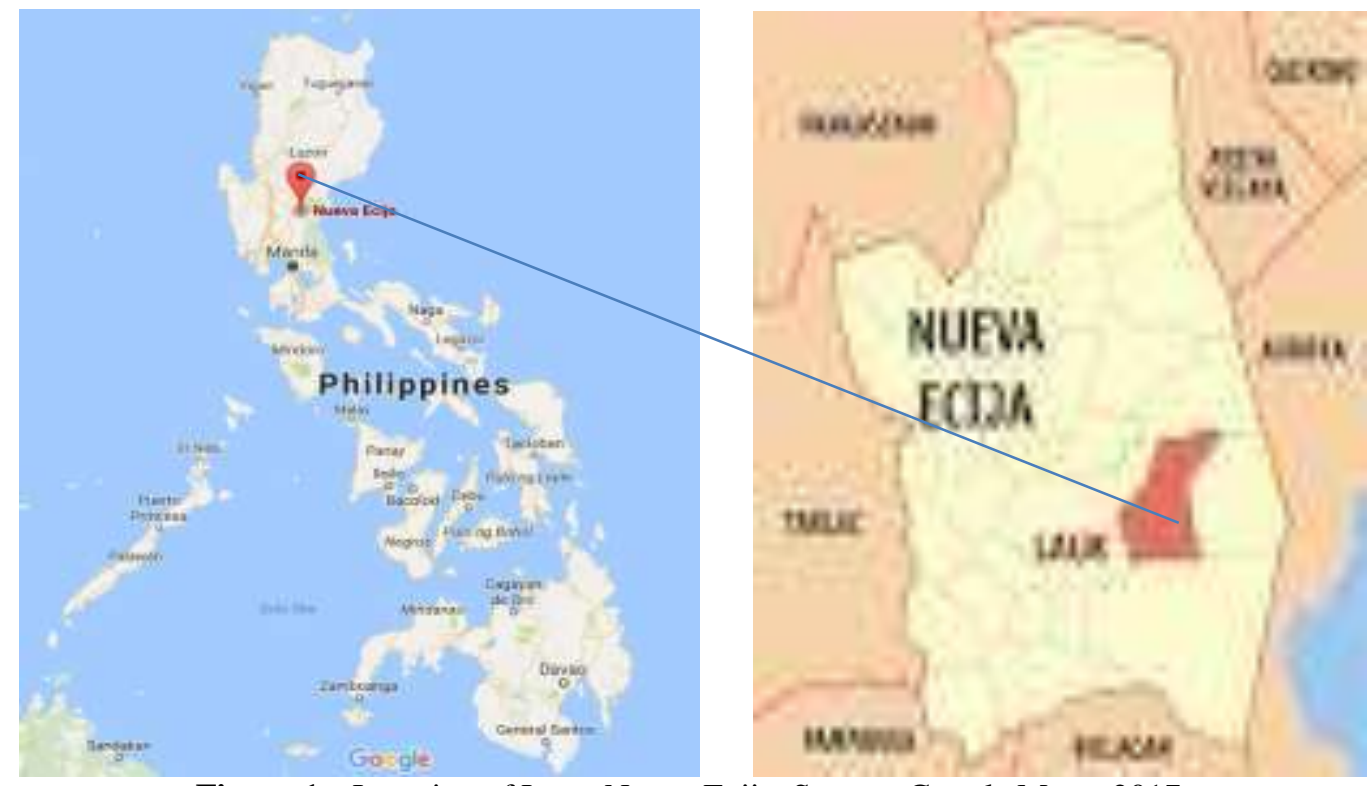

Figure 1:- Location of Laur, Nueva Ecija. Source: Google Maps. 2017. 


\section{Study Design:-}

The study is both qualitative and quantitative in design. The quantitative aspect involved the use of Checklist of Disaster Preparedness while the qualitative part involved the description and determination of effectiveness through the use of observation, interview and analysis of the data observed. Furthermore, the qualitative side of the study focused on describing the how and why of the subject of inquiry using the Goal Model, objectives, and the policies cited. While the quantitative side highlights the measurement of the impact of the BDRRMCs through the relative value of its components, the four thematic areas.

Provided on the checklist are the four thematic areas. Prevention and Mitigation were given 35 points, Preparedness has 30 points, Response has 20, and 15 points was apportioned to Rehabilitation and Recovery. Each thematic area has supporting activities with corresponding points that would meet the objectives set in this study. The point system would be all or nothing. Every maximum point specified is based on the weight or importance of the activity. The first two thematic areas were given large points to satisfy the provisions of the laws and policies cited earlier, the NDRRMF, and NDRRMP. The points from the four thematic areas are totaled using the Microsoft Excel to derive the effectiveness. Thus, the Effectiveness Index yielded the following Score and its Verbal Description, to wit;

\begin{tabular}{|c|c|}
\hline Verbal Description & Score \\
\hline Most Effective: & $91 \%-100 \%$ \\
\hline Much Effective: & $81 \%-90 \%$ \\
\hline Effective: & $71 \%-80 \%$ \\
\hline Least Effective: & $51 \%-70 \%$ \\
\hline Ineffective: & $0 \%-50 \%$ \\
\hline
\end{tabular}

\section{Respondents:-}

The respondent-barangays are the flood and landslide prone barangays of Laur, Nueva Ecija. The flood and landslide prone barangays were selected based on the information gathered from the Laur Disaster Risk Reduction and Management Office (MDRRMO). According to the MDRRMO, out of 17 barangays in Laur, seven (7) are high risk to flooding and landslide, six (6) are medium risk, and the rest are low risk to flooding. Based on a 50\% normal distribution, with 95\% Confidence Level, 15\% Margin of Error, and a population sample of 17 barangays, the sampling yielded a sample size of 7 barangays.

They are the following:

\begin{tabular}{|l|l|}
\hline 1 & Brgy. Betania \\
\hline 2 & Brgy. San Antonio \\
\hline 3 & Brgy. San Fernando \\
\hline 4 & Brgy. Siclong \\
\hline 5 & Brgy. San Vicente \\
\hline 6 & Barangay San Felipe \\
\hline 7 & Brgy. IV \\
\hline
\end{tabular}

These barangays are high-risks and very high-risk in terms of flooding and landslide in the municipality. And they are the barangays that are easily affected of Santor River near the confluence of Pampanga River, it is a critical area perennially affected by high level floods. The respondents of the study were seven (7) Barangay Captains and seven (7) Barangay Secretaries. The Barangay Captain, as chief executive, is the one enforcing laws and ordinances which are applicable within the barangay for the general welfare of the community [10]. While the Barangay Secretary, as an appointive barangay official, is the one in charge of all barangay records. Thus, the Barangay Captain and or the Secretary are the appropriate respondents of this study to ensure validity of the data gathered.

\section{Theoretical Framework:-}

This study is guided by the principles of Organization Theory. There have been several studies regarding organizations, its functions and systems, which led to organization theories. Önday (2016) and Yang, et al. (2013) cited Zhu (1999) and defined organization theory as, "knowledge systems which study and explain organizational structure, function and operation and organizational group behavior and individual behavior" [11] [12] [13]. Under organization theories is the measure of organizational effectiveness. And one of the earliest models of organizational 
effectiveness is the Goal Model. Hall (1980) and Henri (2004) referred to Goodman et al. (1977) and stated that Goal Model is a rational model or set of arrangements and assumptions oriented toward the achievement of goals of the organization [14] [15] [16]. Meanwhile, Etzioni (1977) described effectiveness as the degree to which an organization accomplishes its goals or outcome [17]. The focus of this model is exclusively on the end result or output which is the achievement of goals, objectives, and targets [16]. Hence, the measure of effectiveness is the outcome of organizational activities in terms of measurable outputs [18]. This implies that organizational effectiveness is based on quantifiable activities/outcomes as a result of the BDRRMCs observance and implementation of policies.

\section{Conceptual Framework:-}

From the afore-cited theoretical the following conceptual framework guided the data gathering for the study. The figure below shows the research paradigm of this study. It posits that the Organizational Effectiveness is measured by the number of activities fully implemented by the BDRRMC for every thematic area (Figure 2).

Figure 2: Research Paradigm

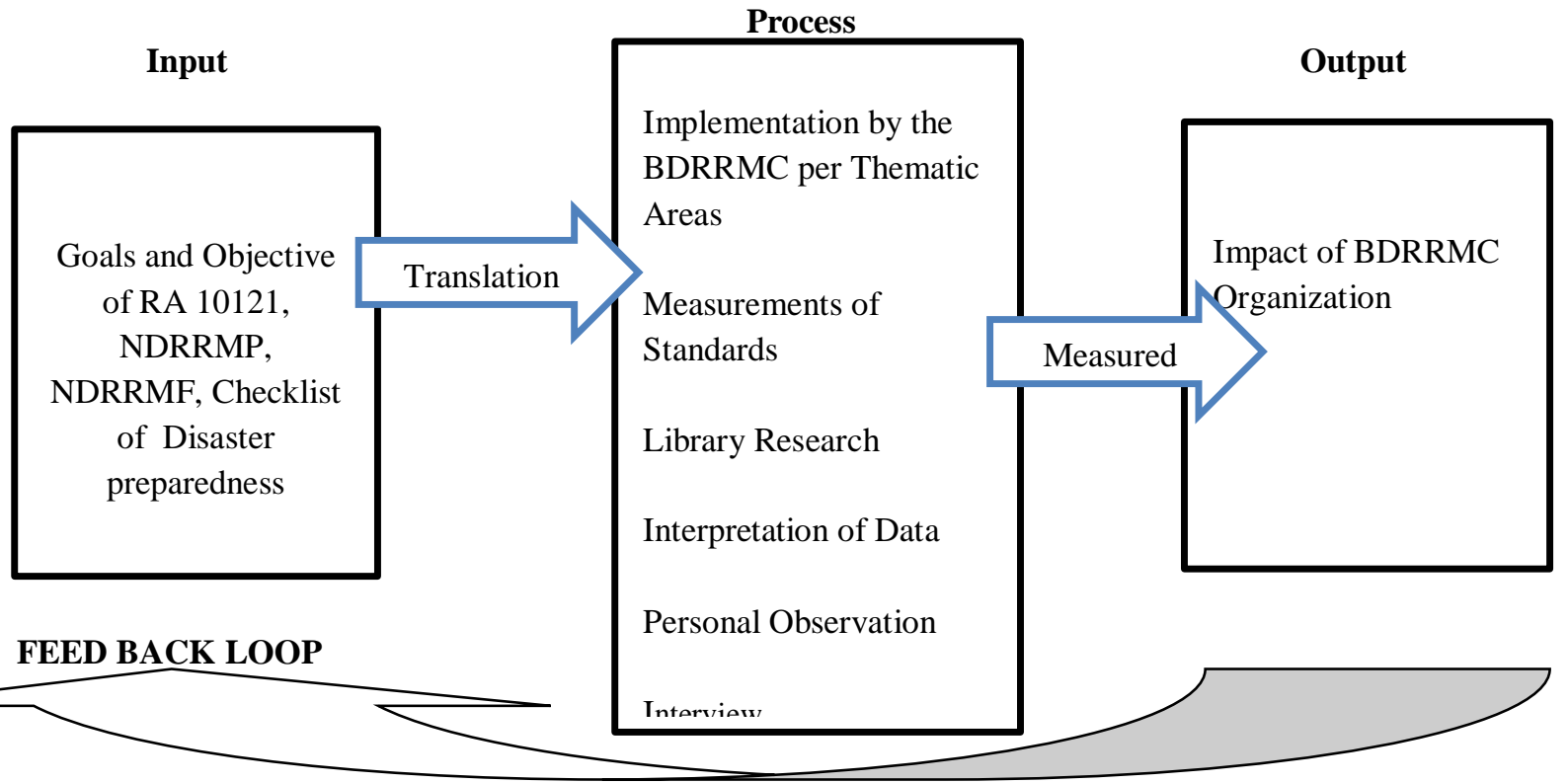

As the paradigm shows, box 1 contains the inputs to be used in the study such as RA 10121, NDRRMP, NDRRMF, and Checklist of Disaster Preparedness. The inputs were processed by the implementation of the policies and BDRRMC functions, and as provided by the throughput box above. Thus, would measure the output of this study, the BDRRMC Organizational Effectiveness. The research output shall again form part of the feedback loop, it may be perceived as the trial and testing of the policy. In return, it may be used whether or not to amend or revise the existing policy on disaster management. Also, to create a suitable standard performance/awareness measurement on the subject matter.

The cycle of input-process-output continues.

\section{Results and Discussion:-}

Presented are the data gathered and their interpretation based on the theory, model, objectives, and policies cited above. The legend below will be consistently used on the presentation of the data of the barangays.

\begin{tabular}{|l|l|}
\hline A & Brgy. Betania \\
\hline B & Brgy. San Antonio \\
\hline C & Brgy. San Fernando \\
\hline D & Brgy. Siclong \\
\hline
\end{tabular}




\begin{tabular}{|l|l|}
\hline E & Brgy. San Vicente \\
\hline F & Barangay San Felipe \\
\hline G & Brgy. IV \\
\hline
\end{tabular}

Legend

\section{Disaster Prevention and Mitigation:-}

The data on Figure 3 shows the scores of the seven barangays in terms of prevention and mitigation. 3 barangays (43\%) have achieved full 35 points, while 2 barangays got the lowest score of 11 points (C and $\mathrm{G})$. The barangays which attained the full score on this thematic area infers their adherence to the objectives of the RA 10121, NDRRMP, and NDRRMF. Also, based on the table, 2 barangays (28.5\%) have achieved 20 points below (D and E) which means they have not attained $50 \%$ of the total score on disaster prevention and mitigation. Thus, indicates that prevention and mitigation activities have not been a priority of the barangay.

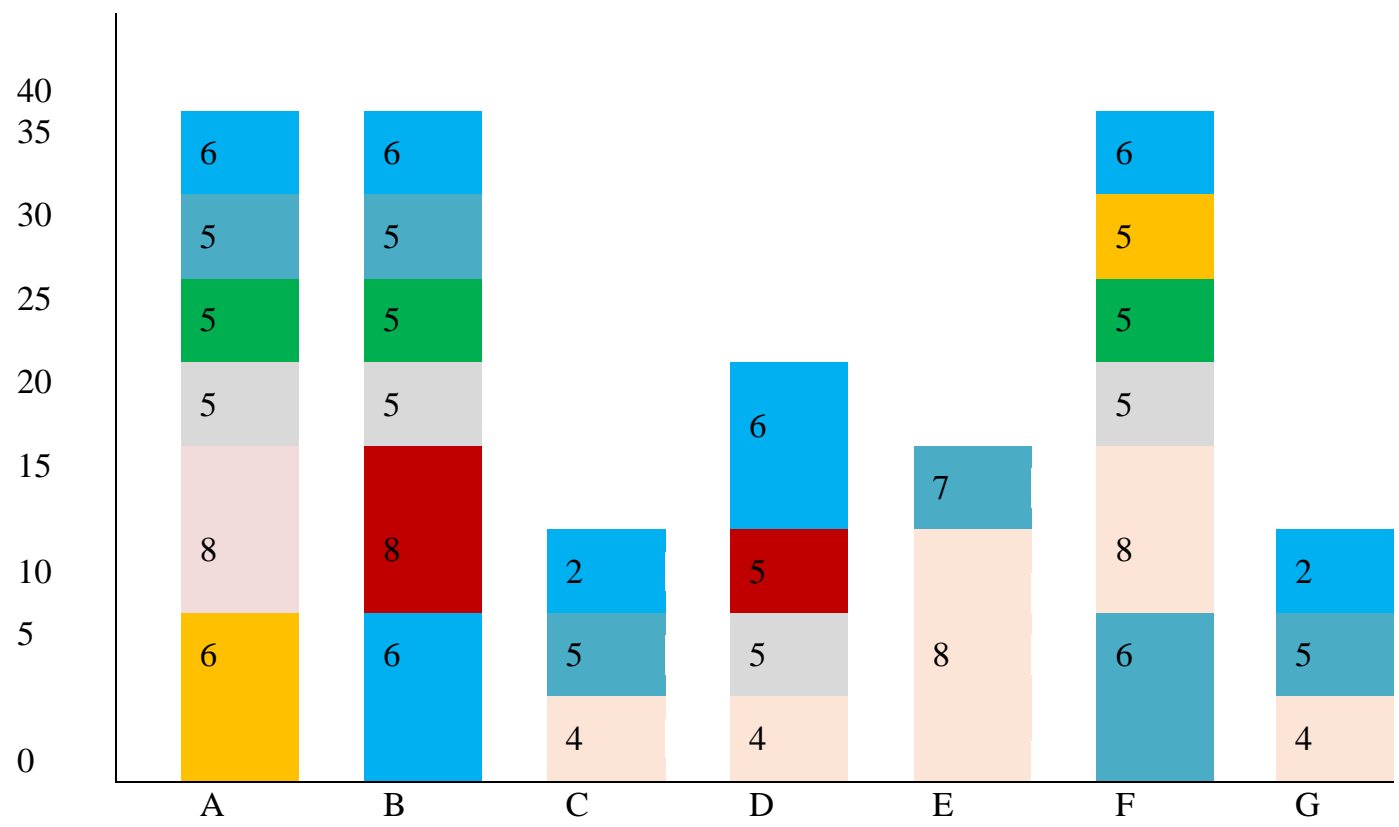

Figure 3:- Disaster Prevention and Mitigation.

\section{Risk Assessment 4.Risk Financing}

2.Plans, policies, budget

5.Environmental Management
3. Early Warning System

6.Infrastructure Resilience

Based on the interview and observation of the researcher, Early Warning System and Risk Assessment activities are in place in all barangays but they do not have the clear idea what they are already doing fall under these activities. This indicates that the policies given to the barangays should be clear and specific in order for the grassroots level to understand and identify the provisions of the law. Barangays which do not conduct Risk Assessment activities rely only on the budget of their barangays and do not source out fund from financial institutions. As shown in the figure, it indicates the priority projects in order to prevent and lessen the impacts of disaster in the community. It depicts enactment and implementation of policies, which is the backbone of disaster management. It focuses on activities which has long term impact on the community. This thematic area is vital on determining whether or not the BDRRMCs are effective on doing what the law mandates. Thus, it is essential in the measurement of effectiveness of the BDRRMCs. However, enactment and implementation of policies requires people's participation. According to Mangahas (2016), the effectiveness of public policy rests in effective implementation [19]. Gutierrez (2017) also pointed out that creation of enabling laws in local government is not enough to create enabling environment. Enabling environment is when people's participation in local legislation provides them sense of ownership of the policies which are useful for effective implementation [18]. 


\section{Disaster Preparedness}

As indicated on Figure 4, it illustrates the capacity and capability of the BDRRMCs on preparing for any kinds of disaster. This depicts the structure, mechanism, activities, and trainings funded to ensure that the goals on DRRM are achieved. It is shown on the figure that Barangay A and F got the highest score with 27 points. However none of the barangays achieved the full 30 points in disaster preparedness. Nevertheless, 5 barangays achieved more than $50 \%$ (15 points) of the total score in this area depicting that the barangays are equipping themselves even before any disaster strikes, which is one of the key to be effective in disaster management. This shows that they have learned from their experiences and are now prepared for any calamities that may arise. On the figure, only 3 barangays (A, B, F) lack approved plans such as BDRRM Plan, Contingency Plan, and Evacuation Plan. However, none of the 7 barangays attained the maximum points on capacity development activities showing that the barangays need to prioritize and appropriate more funds on trainings and skills development for efficient disaster management and service delivery to the community. Basically, this thematic area is about community preparation and participation. And participatory approach is the best way to make the community realize how vulnerable they are [20]. Therefore, the BDRRMCs should encourage people's participation to efficiently manage disasters or emergencies which is the essence of the R.A. 10121.

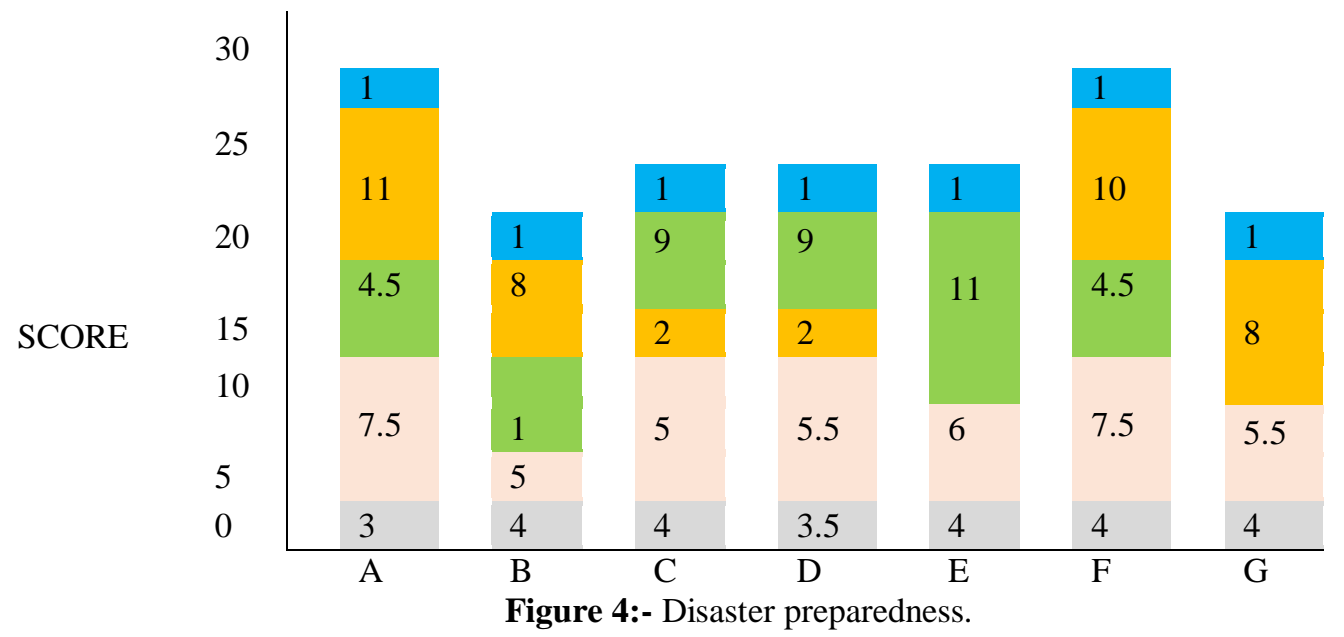

1. Is there a functional Barangay Development Council (BDC)

2. Is there an institutionalized Barangay DRRM Committee

3. Approved plans

4. Capacity Development Activities conducted

5. Partnership Mechanisms

\section{Disaster Response:-}

Reference provides a detailed definition of Disaster Response [3]. Under this area are the systems on evacuation, relief distribution mechanism, coordination, rapid damage assessment and needs analysis, and on time reporting of the barangay to appropriate agencies. This thematic area presents what the barangay should do during emergencies and calamities. The data on Figure 5 reveals that only 1 barangay (D) got the full 20 points, 2 barangays (C, G) got no points at all, but the rest of the barangays (4 barangays) have scored 11 to 17 points or at least more than $50 \%$ of the maximum score for this area. This indicates that the barangays are equipped and are able to display their capability during disaster. Based on its definition and the performance of the BDRRMCs, an effective disaster response is through an effective system of managing a disaster or an emergency. The figure clearly shows that barangays perform well during disaster and they are practicing what they need to do in times of calamities. As mentioned, effective implementation of the policies and program requires the participation of the community. And each decision and action taken by society makes it more vulnerable or more resilient to disasters [20]. Training on proper response during emergencies would help the barangays to be effective on disaster response. This implies that effective disaster preparedness will result to effective disaster response. Hence, successful response measures are indication of successful preparations [21]. This denotes the importance and interrelatedness of each thematic area with each other. The performance of the barangays in one area will have an effect on their performance on the other areas. This is true in disaster response. If the people know what to do and follow the specified early warning and 
evacuation procedure (disaster preparedness) the need for emergency services and public assistance in times of disaster would be reduced (disaster response) [Ibid.].

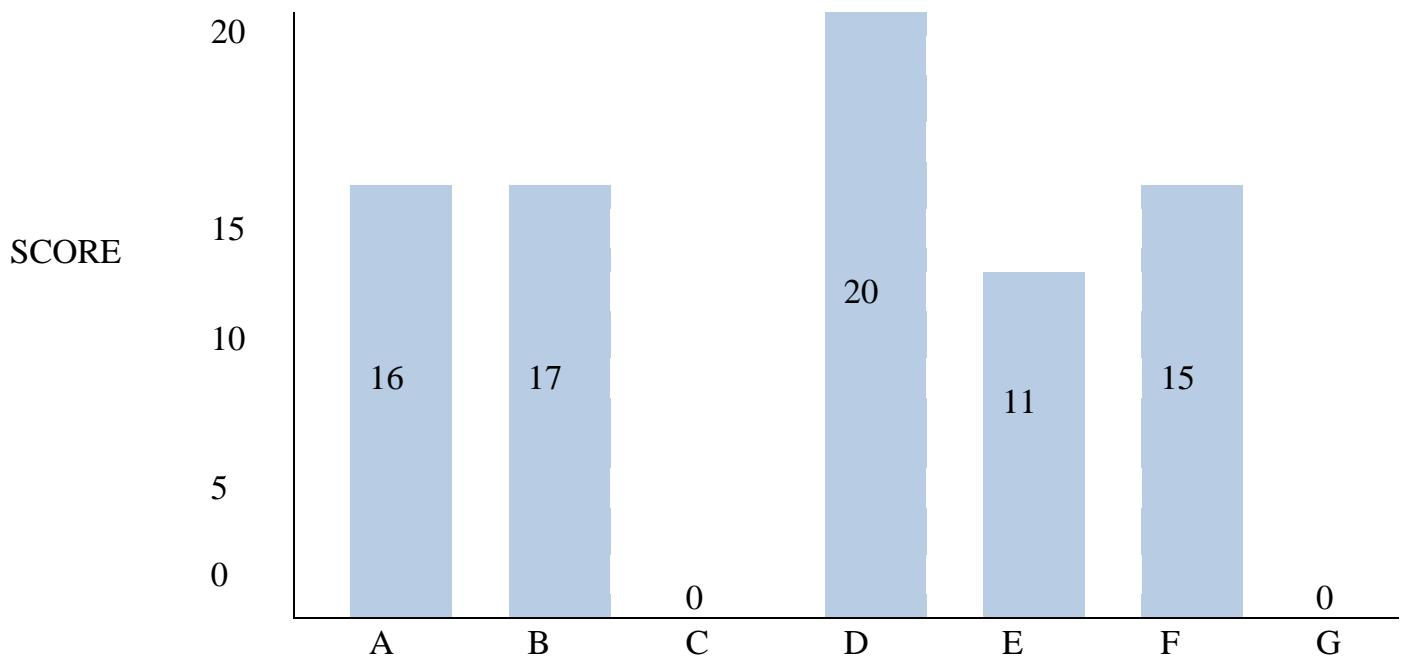

Figure 5:- Disaster response.

Demonstrated Capacity (with disaster response operation)

\section{Disaster Rehabilitation and Recovery:-}

After calamity strikes, a systematic process of preparing for rehabilitation and recovery should be done. This involves post-damage needs assessment (PDNA), restoration activities, and recovery plan to abide by the build-back better principle of the NDRRMP and prevent another disaster to happen. This area involves multi-sectoral and multidisciplinary approach as it covers estimation and valuation of losses, damages, and needs in agriculture, services, trade, etc. While the BDRRMC is not mainly responsible for the valuation and estimation, it could assist the city/municipal government in identifying the needs of the barangay [22]. As shown in Figure 6, 5 barangays got 15 full points. Based on the table, 2 barangays attained 8 points below, which is $50 \%$ of the maximum score on rehabilitation and recovery. This suggests that $29 \%$ of the barangays do not have enough activities on rehabilitation and recovery considering that all of these barangays are prone to flooding. In here, the capacity of the barangays to return to their normal condition is vital in determining whether the preparedness activities of the barangays are enough to make the community resilient. This infers that in rehabilitation and recovery, it will require not only the effectiveness of the BDRRMCs but also the resiliency of the whole community. This will only be achieved if the BDRRMCs are effective in doing the pre-disaster activities that the law required to them to prioritize.

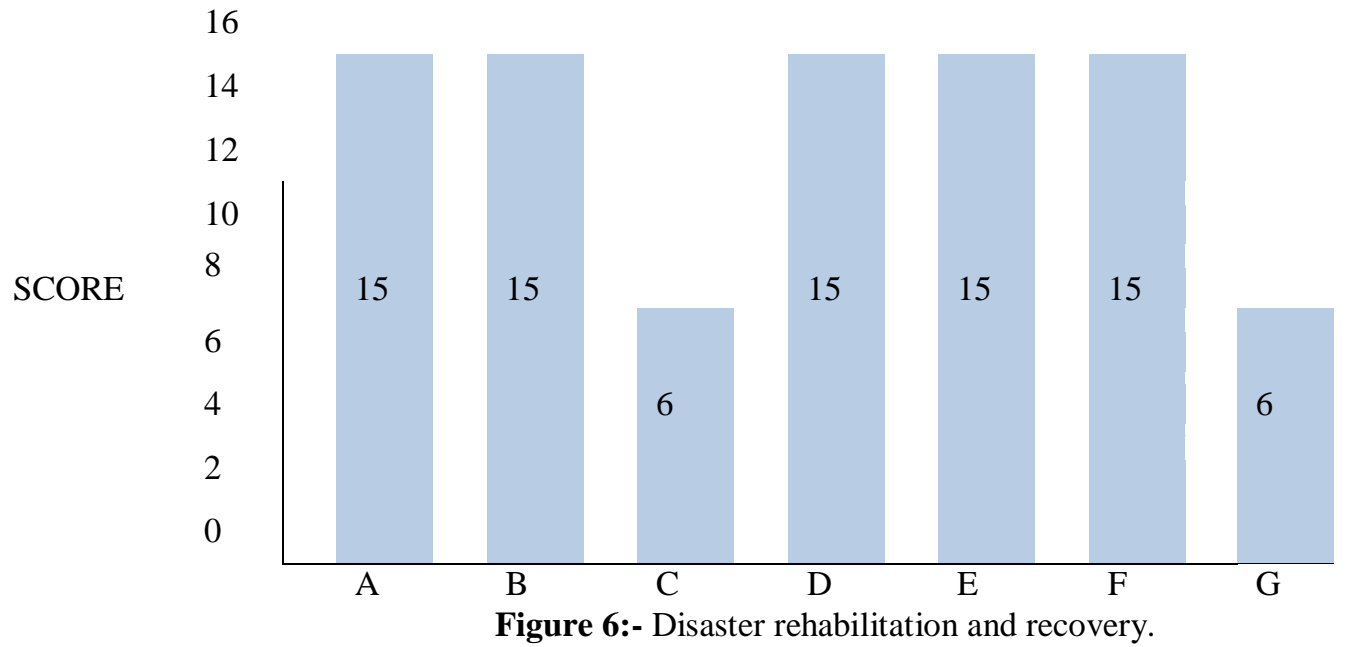




\section{Rehabilitation and Recovery Capacity (with disaster)}

The Effectiveness of the BDRRMCs:-

Table 1:- Effectiveness of the BDRRMCs.

\begin{tabular}{|l|l|l|}
\hline Barangay & Total Score & Description \\
\hline A & 93 & Most Effective \\
\hline B & 86 & Much Effective \\
\hline C & 38 & Ineffective \\
\hline D & 76 & Effective \\
\hline E & 63 & Least Effective \\
\hline F & 88 & Much Effective \\
\hline G & 35.5 & Ineffective \\
\hline
\end{tabular}

Figure 7:- The effectiveness of the BDRRMCs.

The data on Table 1 displays the total scores each barangay has and the verbal description based on the Effectiveness Index used on this study. As presented below, only 1 (14.28\%) barangay (A) are described as Most Effective, followed by $2(28.57 \%)$ barangay which are all defined as Much Effective , another 1 (14.28\%) barangays which is described as Effective , 2 barangays (14.28\%) is Least Effective, while 1 barangays (28.57\%) is described as Ineffective. As indicated on Figure 7, it shows that the highest score were achieved by barangay A (93 points) followed by F (88), B (86) and D (76). Indicating the results of the four thematic areas discussed, clearly identify that the organizational effectiveness of BDRRMCs are achieved if they adhere to the law by implementing all the activities of the four thematic areas. The Most Effective barangays shown above, specifically barangay A, is consistent in achieving the top scores in all four thematic areas, the same goes with the four Ineffective BDRRMCs wherein. Hence, shows that the effectiveness of the BDRRMCs must be measured as the total of the four thematic areas due to their interrelatedness with each other. The findings of this study clearly reveal that performance measurement is a vital element in the successful operation of performance management in the public service [23]. The performance of the BDRRMCs in the four thematic areas, as reflected by their organizational effectiveness, definitely ensures the attainment of the goal of the R.A. 10121. And for the policies to be appreciated by the community, sufficient public involvement in local decision making is needed to ensure that primary objectives of the policies reflect community concern [24]. This way the effective implementation and performance of the barangays will be assured.

\section{Conclusion and Recommendations:- Conclusion:-}

The purpose of this study was to measure the organizational awareness and disaster preparedness of the BDRRMCs based on the four thematic areas. And based on the findings, the following conclusions can be drawn from this study. The four thematic areas are interrelated to each other so it really requires the result of each thematic area to assess the effectiveness of the BDRRMCs. The BDRRMCs will be most effective if they are performing their functions. And as prescribed by the law, they should give priorities to all thematic areas, especially prevention and mitigation, and disaster preparedness to achieve the goals and objectives of RA 10121. This way, not only will the barangay be benefitted but the whole community and municipality as well. R.A. 10121, NDRRMP, and NDRRMF already provided the essential activities in DRRM. It is up to the people, especially the barangays, how they would appreciate the policies and how they would implement it. But the performance of the barangays on DRRM should be assessed. Rather, there should be a standard on performance and effectiveness measurement to be able to test the policies and somehow revise or amend it based on the performance of the barangay.

\section{Recommendations:-}

Based on the existing policies and the findings of this study, the researcher arrived to the following recommendations:

\section{1) For the government}

a) The researcher recommends the government to establish a standard performance and effectiveness measurement on DRRM per thematic areas, to all levels of the government, specifically to the barangays. 
b) To effectively cascade the existing policies on DRRM, the national government should revisit the R.A. 10121 and make its Implementing Rules and Regulations be more detailed, specific, and inclusive for the LGUs to easily appreciate and implement it.

c) The national and local governments should strictly implement the policies regarding DRRM and those integrated in it such as Zoning Ordinance, CLUP, and Climate Change Adaptation Plan.

\section{2) For the Barangays}

a) The researcher recommends that the barangay should prioritize Disaster Prevention and Mitigation and Disaster Preparedness activities to effectively and efficiently manage any types of disaster.

b) Since disaster is unpredictable, the barangay should always have plans such as DRMM plan, contingency plans, evacuation plan, and recovery plan to properly respond to any types of disaster.

c) The barangay should also encourage peoples' participation to effectively implement the policies on DRRM.

d) The barangay should prioritize DRRM activities in its area to effectively manage any types of disaster.

e) The researcher recommends that the Barangay should adhere to the Laur Local Climate Change Adaptation Action plan .

f) The knowledge, attitude and practices on DRRM must be sustained and must be passed from generation to generation as these are important strengths that a community should have in times of the inevitable natural disasters. Thus, the conduct of information, education and communication campaign, drills and training on DRRM must be enforced and be always practiced. To carry out these activities, they have to collaborate with government organizations and Non-Government Organizations who have specific programs related to DRRM plans and guidelines.

g) The barangay council should coordinate with other agencies to address the psychological needs of affected constituents every after disaster

\section{References:-}

1. (http://www.ifrc.org/Global/Case\%20studies/Disasters/cs-philippines.pdf )

2. National Disaster Risk Reduction and Management Plan (NDRRMP), 2011-2028.

3. Republic Act 10121, Philippine Disaster Risk Reduction and Management Act of 2010.

4. National Disaster Risk Reduction and Management Framework (NDRRMF), 2011.

5. Gabriel, A.G. and Manuzon, E.D.P. (2016) Management, Decision Making Styles and Training Preferences of Barangay Officials in Nueva Ecija Philippines. North Asian International Journal of Social Sciences and Humanities, 2, 93-110.

6. Municipality of Laur, Nueva Ecija Hazard, Vulnerability and Risk Assessment 2017

7. Seal of Good Local Governance: Pagkilala sa kahusayan at katapatan ng Pamahalaang

8. Lokal, DILG Memorandum Circular No. 2014-39, 2014.

9. Revised Guidelines on the "Gawad KALASAG": Search for Excellence in Disaster

10. Risk Reduction and Management (DRRM) and Humanitarian Assistance 2013, NDRRMC Memorandum Circular No. 02 s. 2013.

11. Guthrie, J. and English, L. (1997) Performance Information and Program Evaluation in the Australian Public Sector. International Journal of Public Sector Management, 10, 154-164. https://doi.org/10.1108/09513559710166039

12. Republic Act 7160, "The local government code of the Philippines," 1991.

13. Önday, Ö. (2016) Classical Organization Theory: From Generic Management of Socrates to Bureaucracy of Weber. International Journal of Business and Management Review, 4, 87-105. http://www.eajournals.org/

14. Yang, C., Liu, H. and Wang, X. (2013) Organization Theories: From Classical to modern. Journal of Applied Science, 13, 4470-4476. https://doi.org/10.3923/jas.2013.4470.4476

15. Zhu, G. (1999) Organization Theory: History and Genre. Nanjing University Press,

16. Hall, R.H. (1980) Effectiveness Theory and Organizational Effectiveness. The Journal of Applied Behavioral Science, 16, 536-545. http://journals.sagepub.com/ https://doi.org/10.1177/002188638001600408

17. Henri, J.-F. (2004) Performance Measurement and Organizational Effectiveness: Bridging the Gap. Managerial Finance, 30, 93-123. https://doi.org/10.1108/03074350410769137

18. Goodman, P.S., Pennings, J.M., et al. (1977) New Perspectives on Organizational Effectiveness. Jossey-Bass Publishers, San Francisco, London.

19. Etzioni, A. (1960) Two Approaches to Organizational Analysis: A Critique and Suggestion. Administrative Science Quarterly, 5, 257-258. https://doi.org/10.2307/2390780 
20. Gabriel, A.G. and Gutierrez M.P. (2017) Praxis in Local Legislative Governance: A Correlation Analysis of Governance Principles and Local Legislative Performance as Measure of Organizational Effectiveness of the Component Cities in Nueva Ecija, Philippines. Asia Pacific Journal of Multidisciplinary Research, 5. http://www.academia.edu/

21. Gabriel, A.G. and Mangahas, T.L. (2016) Revisiting the Anti-Hazing Law in Selected Higher Education Institutions in Nueva Ecija, Philippines: A Policy Review. Open Access Library Journal, 3, e3177. https://doi.org/10.4236/oalib.1103177

22. Rahman, K. and Hashi, N.A. (2015) Participatory Earthquake Vulnerability Assessment: A Case Study on Motijhorna Slum. International Conference on Mechanical Engineering and Renewable Energy (ICMERE2015), Chittagong, Bangladesh, 26-29 November 2015. https://www.academia.edu/

23. UNISDR (2016) What Is Disaster Risk Reduction? The United Nations Office for Disaster Risk Reduction. https://www.unisdr.org/who-we-are/what-is-drrl

24. Community-Based Disaster Risk Reduction and Management, Basic Instructors' Guide (BIG). OCD-JICA Project Disaster Risk Reduction and Management Capacity Enhancement.

25. Boyle, R. (2000) Performance Measurement in Local Government. CPMR Discussion Paper 15.

26. Kloot, L. and Martin, J. (2000) Strategic Performance Management: A Balanced Approach to Performance Management Issues in Local Government. Management Accounting Research, 11, 231-251. http://www.idealibrary.com/ 